Novel silica based adsorbent layer-by-layer modified with

polyhexamethylene guanidine and Arsenazo reagents for solid-phase extraction of lanthanides from lignites and products of their processing

Vladimir Losev, Olga Buyko, Sergey Metelitsa, Elena Borodina, Nikolay Kuzmin, Aleksandr Shimanskiy

Scientific Research Engineering Center "Kristall”, Siberian Federal University, pr. Svobodnyi, 79, 660041 Krasnoyarsk, Russian Federation

Corresponding author: Olga Buyko e-mail: bujko86@gmail.com 


\title{
Novel silica based adsorbent layer-by-layer modified with polyhexamethylene guanidine and Arsenazo reagents for solid-phase extraction of lanthanides from lignites and products of their processing
}

\author{
Novel silica based adsorption materials layer-by-layer modified with \\ polyhexamethylene guanidine and Arsenazo I or Arsenazo III have been \\ proposed for solid-phase extraction of rare earth elements (REE). Silica, modified \\ with Arsenazo I, quantitatively extracted REE at pH 5.5 -7.0, and silica, modified \\ with Arsenazo III, at $\mathrm{pH}$ 2.0-6.0 with distribution coefficients of $2.9 \cdot 10^{3}-4.6 \cdot 10^{4}$ \\ $\mathrm{cm}^{3} \mathrm{~g}^{-1}$. The adsorption capacity for REE was $1.25-2.85 \mathrm{mg} \mathrm{g}^{-1}$. Silica, layer-by- \\ layer modified with polyhexamethylene guanidine and Arsenazo III, was used for \\ removal of REE from solutions after digestion of lignites and ashes after their \\ burning.
}

Keywords: solid-phase extraction; silica; layer-by-layer modification; Arsenazo; REE

\section{Introduction}

Lanthanides have unique physical and chemical properties and widely used in various industries, such as lasers, permanent magnets, electronic devices, superconductors and catalysis [1].

Lanthanides are found everywhere in nature, in many minerals, and belong to trace elements. The most important minerals that contain lanthanides are bastnasite, monazite, apatite, loparite, allanite, ancylite, parisite, etc. [2]. Recently, interest has increased not only in traditional sources of rare earth elements (REE), but also in secondary resources, such as ash after burning lignites. Lignites are fragments of fossil wood that has undergone coalification processes and used as a fuel. Ash after burning is not processed usually. However, it contains various critical elements, including REE, and can be considered as a potential source of REE [3-5]. 
Two main approaches to the removal of REE are used: liquid- liquid [6-9] and solid-phase extraction (SPE) $[6,9]$. Despite the widespread use of the first approach, it has significant drawbacks: the need to use organic toxic solvents, low separation efficiency and purity level. Therefore, at present, many scientific publications are devoted to the synthesis and study of adsorption materials for solid-phase extraction of rare earth elements. Adsorbents can be divided into several types: natural clays [10-11], polymeric [12-15], silica [16-19], membrane [20], and microorganisms [21-23]. One of the most available inorganic oxides allowing varying the surface parameters is silica. Adsorbent matrices are usually modified to improve the adsorption properties to REE.

There are two main approaches to surface modification of adsorbents - covalent and non-covalent. Currently, many silicas with chemically fixed groups have been synthesized [24-26]. But, despite the high stability of such adsorbents in solutions of dilute acids and alkalis, their synthesis is characterized by the complexity and use of toxic solvents. Non-covalent modification allows fixing the reagent on the surface of silica without chemical reaction and using toxic solvents.

In present work, silica modified with polyhexamethylene guanidine (PHMG) and Arsenazo I or Arsenazo III was proposed as an adsorbent for solid-phase extraction of lanthanides. The reagents of the Arsenazo group are chosen as the outer layer, since they form stable, intensely colored complexes with REE ions [27-30]. However, direct fixation of these reagents on the surface of silica is impossible because of the mutual repulsion of negatively charged sulfo groups of the reagents and the deprotonated hydroxyl groups of the surface. To fix Arsenazo on the silica surface, an approach has been proposed, which consists of pre-treatment of silica surface with an aqueous solution of polyhexamethylene guanidine and the subsequent modification of the resulting adsorbent with aqueous solutions of Arsenazo. The sequential fixation of 
reagents on the surface of silica occurs due to the formation of non-covalent bonds (electrostatic, hydrogen). The scheme of the adsorbent structure (silica modified with polyhexamethylene guanidine and Arsenazo III as an example) is shown in Fig. 1.

In this work, the conditions for synthesis of novel adsorption silica-based materials, layer-by-layer modified with PHMG and Arsenazo I or Arsenazo III are studied. The adsorbent surface was characterized by Fourier Transform Infrared Spectroscopy (FT-IR) and Diffuse Reflectance Spectroscopy (DRS). The conditions of SPE of lanthanides by new adsorbents in the batch and dynamic modes have been studied.

Silica based adsorbent layer-by-layer modified with polyhexamethylene guanidine and Arsenazo III was used for solid-phase extraction of REE from solutions after digestion of lignites from the Kass deposit located in the middle course of the Yenisei River (Krasnoyarsk Territory, Russia) and ash from their burning.

\section{Materials and methods}

\subsection{Reagents}

Stock solutions of $\mathrm{La}(\mathrm{III}), \mathrm{Er}(\mathrm{III}), \mathrm{Sm}(\mathrm{III}), \mathrm{Ho}(\mathrm{III}), \mathrm{Nd}(\mathrm{III}), \mathrm{Gd}(\mathrm{III})\left(10 \mathrm{mg} \cdot \mathrm{L}^{-1}\right)$ were prepared by dissolving the corresponding REE oxides ( $\geq 99.99 \%$, Sigma-Aldrich, USA) in $1 \mathrm{M} \mathrm{HNO}_{3}$. Solutions with lower concentrations were prepared by diluting of stock solutions.

Stock solutions of $\mathrm{Fe}(\mathrm{III}), \mathrm{Cu}(\mathrm{II}), \mathrm{Pb}(\mathrm{II}), \mathrm{Zn}(\mathrm{II}), \mathrm{Mn}(\mathrm{II}), \mathrm{Ni}(\mathrm{II}), \mathrm{Co}(\mathrm{II}), \mathrm{Fe}(\mathrm{II})$, $\mathrm{Ca}(\mathrm{II}), \mathrm{Mg}(\mathrm{II}), \mathrm{Sr}(\mathrm{II}), \mathrm{K}(\mathrm{I}), \mathrm{Na}(\mathrm{I})$ were prepared by dissolving the corresponding salts (Chemreaktivsnab, Russia) of reagent grade in $0.1 \mathrm{M} \mathrm{HNO}_{3}$.

Polyhexamethylene guanidine chloride was purchased from Institute of Ecotechnological problems (Moscow, Russian Federation). Arsenazo I (2-(1,8-dixydroxy3,6-disulfo-2-naphthylazo)benzenearsonic acid) and Arsenazo III (2,2'-(1,8-Dihydroxy- 
3,6-disulfonaphthylene-2,7-bisazo)bisbenzenearsonic acid) were purchased from

Sigma-Aldrich. Solutions of PHMG and Arsenazo with the concentration of 7.5 and 0.1 $\%(\mathrm{w} / \mathrm{V})$, respectively, were prepared by dissolving accurately weighed portions of reagents in deionized water. Solutions of Arsenazo with lower concentrations were prepared by diluting the initial solution with deionized water.

Nitric acid (Chemreaktivsnab, Russia) of analytical grade was additionally purified by distillation using distillacid ${ }^{\mathrm{TM}}$ BSB-939-IR (Berghof, Germany).

Silochrom C-120 (particle size of $0.1-0.2 \mathrm{~mm}$, specific surface of $\sim 120 \mathrm{~m}^{2} \mathrm{~g}^{-1}$, an average pore size of $\sim 45 \mathrm{~nm}$ ) was purchased from Luminofor (Stavropol, Russian Federation) and used as a matrix for the synthesis of silica based adsorbents.

\subsection{Apparatus}

The UV-Vis spectra were recorded using Lambda 35 spectrophotometer (Perkin-Elmer, USA). Diffuse reflectance spectra (DRS) of adsorbents in the range of 380-720 nm were recorded using Pulsar spectrometer (Khimavtomatika, Russia). The spectra are represented in the coordinates $\mathrm{F}(\mathrm{R})$ (Kubelka-Munk function) - wavelength, nm, where $\mathrm{R}$ - diffuse reflectance coefficient. Metals distribution was monitored by ICP-MS analysis of an aqueous phase using XSeries II mass-spectrometer (Thermo Scientific, USA). To determine the REE concentration by ICP-MS, the following element isotopes were used: ${ }^{139} \mathrm{La},{ }^{140} \mathrm{Ce},{ }^{141} \mathrm{Pr},{ }^{146} \mathrm{Nd},{ }^{147} \mathrm{Sm},{ }^{153} \mathrm{Eu},{ }^{158} \mathrm{Gd},{ }^{159} \mathrm{~Tb},{ }^{163} \mathrm{Dy},{ }^{165} \mathrm{Ho},{ }^{166} \mathrm{Er}$, ${ }^{169} \mathrm{Tm},{ }^{172} \mathrm{Yb},{ }^{175} \mathrm{Lu}$.

The $\mathrm{pH}$ of the solutions was measured using a SevenMulti ion meter (MettlerToledo, Switzerland). A Masterflex peristaltic pump (Cole-Parmer Instruments Company, USA) was used for pumping fluids through the preconcentration column with an adsorbent. 
The adsorbents were analyzed by Fourier Transform Infrared Spectroscopy using spectrometer Nicolet 380 with Smart Orbit accessories (Thermo scientific, USA) in wavelength range of $3000-400 \mathrm{~cm}^{-1}$ with $4 \mathrm{~cm}^{-1}$ spectral resolution.

The muffle furnace SNOL 7.2/1100 (Utenos Electrotechnika, Lithuania) was used for lignite samples firing.

\subsection{Sequential modification of silica surface with polyhexamethylene guanidine and Arsenazo I or Arsenazo III}

In order to activate the surface a portion of silica was soaked with the $\mathrm{NaOH}$ solution at $\mathrm{pH} 9$ for 2 hours, and then washed with deionized water until $\mathrm{pH}$. Then $100 \mathrm{~mL}$ of PHMG solution (7.5\%) was added dropwise for $30 \mathrm{~min}$ to $5 \mathrm{~g}$ of silica under continuous stirring. The adsorbent $\left(\mathrm{SiO}_{2}-\mathrm{PHMG}\right)$ was washed with deionized water until no positive reaction to PHMG in the rinsing water and dried at $60^{\circ} \mathrm{C}$. Presence of PHMG in the rinsing water was determined visually by the test with bromophenol blue.

In order to investigate the adsorption capacity of $\mathrm{SiO}_{2}-\mathrm{PHMG}$ for Arsenazo I (or Arsenazo III) $5 \mathrm{~mL}$ of $1 \cdot 10^{-7}-2 \cdot 10^{-3} \mathrm{M}$ solution of Arsenazo I (or Arsenazo III) was placed into a graduated test tube with a glass stopper; $\mathrm{HNO}_{3}$ or $\mathrm{NaOH}$ were added to adjust the required acidity; and water was added to a total volume of $10 \mathrm{~mL}$. Then, $0.1 \mathrm{~g}$ of the adsorbent was added, the tube was stopped and stirred for 10 minutes. The solution was decanted and the resulting adsorbent $\left(\mathrm{SiO}_{2}-\mathrm{PHMG}-\mathrm{ArsI}\right.$ or $\mathrm{SiO}_{2}-\mathrm{PHMG}-$ ArsIII) was washed with deionized water and air dried overnight.

Aliquots of the reagent solutions before and after adsorption were placed into a quartz cuvette $(1=1.0 \mathrm{~cm})$ and the absorbance was measured at the characteristic absorption band of the reagent $\left(\lambda_{\max }=500 \mathrm{~nm}\right.$ for Arsenazo I, $540 \mathrm{~nm}$ for Arsenazo III). The amount of the adsorbed reagent was determined by the difference in the reagent concentrations in the solution before and after adsorption. 


\subsection{Solid-phase extraction of lanthanides by $\mathrm{SiO}_{2}-\mathrm{PHMG}$-AarsI (or $\mathrm{SiO}_{2-}$ PHMG-ArsIII) adsorbent}

Solid-phase extraction of lanthanides by $\mathrm{SiO}_{2}$-PHMG-Ars was studied in the batch and dynamic modes at room temperature. In the batch mode, a solution of the REE in $0.1 \mathrm{M}$ $\mathrm{HNO}_{3}$ was added to graduated test tube with a glass stopper, $\mathrm{NaOH}$ was added to adjust the required acidity and water to a total volume of $10 \mathrm{~mL}$, or buffer solutions were used. $0.1 \mathrm{~g}$ of the adsorbent was added to the solution, the tube was stopped and stirred for 160 minutes.

In the dynamic mode, a solution containing REE was passed through a column (height $4.5 \mathrm{~cm}, \mathrm{~d}=0.3 \mathrm{~cm}$ ) filled with $0.1 \mathrm{~g}$ of the adsorbent at a flow rate of $1-5 \mathrm{~mL}$ $\min ^{-1}$

\subsection{Sample preparation of lignites and ash}

Lignites and ashes from their burning were used as real samples. Samples of lignite of $1.0000 \mathrm{~g}$ were placed in ceramic crucibles and ashed in a muffle furnace at a temperature of $550^{\circ} \mathrm{C}$ for 4 hours. The resulting ash was placed in $100 \mathrm{~mL}$ glassy carbon beakers, $10 \mathrm{~mL}$ of concentrated $\mathrm{H}_{3} \mathrm{PO}_{4}$ and $5 \mathrm{~mL}$ of concentrated $\mathrm{HNO}_{3}$ were added, heated to $130^{\circ} \mathrm{C}$ and evaporated to a syrupy state. $25 \mathrm{~mL}$ of deionized water was added, mixed and transferred to a $50 \mathrm{~mL}$ volumetric flask and filled to the mark with water. For preparation of a lignite ash sample of $0.1000 \mathrm{~g}$ was taken and acted as described above.

\subsection{Calculations}

The Kubelka-Munk function $(\mathrm{F}(\mathrm{R}))$ was calculated as:

$$
F(R)=(1-R)^{2} / 2 \cdot R
$$


$R$ - diffuse reflectance coefficient.

The extraction efficiency $\left(\mathrm{R}_{\mathrm{ex}}, \%\right)$ of Arsenazo or REE extracted by adsorbents was determined as follows:

$$
R_{e x}=\left[\left(C_{0}-C_{e}\right) / C_{0}\right] \cdot 100 \%
$$

$C_{0}$-initial concentration of Arsenazo or REE in the solution, $\mathrm{mmol} \mathrm{L}^{-1}$,

$C_{e}$-equilibrium concentration of Arsenazo or REE in the solution, $\mathrm{mmol} \mathrm{\textrm {L } ^ { - 1 }}$.

The desorption efficiency $\left(\mathrm{R}_{\mathrm{des}}, \%\right)$ of Arsenazo or REE was determined as follows:

$$
R_{d e s}=\left[C_{d e s}\left(C_{0}-C_{e q}\right)\right] \cdot 100 \%
$$

$C_{d e s^{-}}$concentrations of Arsenazo or REE in the desorption solution, $\mathrm{mmol} \mathrm{L} \mathrm{L}^{-1}$.

The adsorption properties of $\mathrm{SiO}_{2}-\mathrm{PHMG}-\mathrm{ArsI}$ and $\mathrm{SiO}_{2}-\mathrm{PHMG}-\mathrm{ArsIII}$ for REE extraction vs. phase contact time were analyzed using pseudo-first-order Eq. (4):

$$
\ln \left(q_{e^{-}} q_{t}\right)=\ln q_{e^{-}} k_{1} t
$$

and pseudo-second-order model Eq. (5):

$$
t / q_{t}=1 /\left(k_{2} q_{e}^{2}\right)+t / q_{e}
$$

$q_{e}\left(\mathrm{mg} \mathrm{g}^{-1}\right)$ and $q_{t}\left(\mathrm{mg} \mathrm{g}^{-1}\right)-$ the amounts of REE ions adsorbed at equilibrium and at time $t$, respectively,

$k_{1}$ and $k_{2}$ - the rate constants of the pseudo-first- order and pseudo-second-order models, respectively.

The quantity of Arsenazo or REE extracted $\left(q, \mathrm{mmol} \mathrm{g}^{-1}\right)$ by adsorbents was calculated from Eq.(6): 


$$
q=\left[\left(C_{0}-C_{e}\right) \cdot V\right] / m
$$

$V$ - the solution volume, $\mathrm{L}$,

$m$-the mass of adsorbent, $\mathrm{g}$.

The isotherms of REE adsorption were analyzed using two traditional models Langmuir Eq. (7) and Freundlich Eq. (8):

$$
C_{e} / q_{e}=1 /\left(K_{L} \cdot q_{\max }\right)+C_{e} / q_{\max }
$$

$q_{e}{ }^{\prime}-$ the amounts of REE ions adsorbed at equilibrium, mmol g ${ }^{-1}$

$q_{\max }$ - the maximum adsorption amount of REE ions, $\mathrm{mmol} \mathrm{g}^{-1}$,

$K_{L}$ - the Langmuir constant related to the energy of adsorption process and the maximum adsorption capacity, $\mathrm{L} \mathrm{mmol}^{-1}$. These constants were calculated from the intercept and the slope of plotting $\mathrm{C}_{\mathrm{e}} / \mathrm{q}_{\mathrm{e}} \mathrm{vs}$. $\mathrm{C}_{\mathrm{e}}$, respectively.

$$
\ln q_{e}=\ln K_{F}+(1 / n) \ln C_{e}
$$

where both $K_{F}$ and $n$ are Freundlich isotherm constants.

\section{Results and Discussion}

\subsection{Optimization of the conditions for $\mathrm{SiO}_{2}-\mathrm{PHMG}$-Ars synthesis}

The time of attainment of adsorption equilibrium during the extraction of Arsenazo I (Arsenazo III) with $\mathrm{SiO}_{2}$-PHMG adsorbent was less than 10 minutes.

Quantitative extraction (99.9\%) of reagents was observed in the $\mathrm{pH}$ range of

\section{5-8.0 (Fig. 2).}

The decrease in extraction degree in the $\mathrm{pH}$ range 1.0-3.0, for both reagents, is probably due to a change in the mechanism of PHMG fixation on the surface of silica from electrostatic at $\mathrm{pH}>3$ to the formation of a hydrogen bond at $\mathrm{pH}<3$. Therefore, at 
$\mathrm{pH} 2$ there was a decrease in the extraction degree of PHMG, and at $\mathrm{pH} 1$ there was an increase one.

When passing from 0.1 to $2 \mathrm{M} \mathrm{HCl}$, the extraction of reagent decreased. This is due to the protonization of sulfo groups of Arsenazo I $\left(\mathrm{pK}_{\mathrm{a} 1}=0.07\right.$ и $\left.\mathrm{pK}_{\mathrm{a} 2}=1.16\right)$ and Arsenazo III $\left(\mathrm{pK}_{\mathrm{a} 1}=0.64\right.$ и $\left.\mathrm{pK}_{\mathrm{a} 2}=2.52\right)$ [31] through which Arsenazo I and Arsenazo III are fixed on the surface of $\mathrm{SiO}_{2}$-PHMG.

To determine the capacity of $\mathrm{SiO}_{2}$-PHMG for the reagents, the adsorption isotherms of Arsenazo I and Arsenazo III were constructed (Fig. 3).

The capacity of the $\mathrm{SiO}_{2}$-PHMG adsorbent for Arsenazo III is almost 2 times less than that for Arsenazo I, which can be explained by an increase in the size of the molecule. Since the reagents on the surface of the adsorbent are interconnected by weak intermolecular bonds that can be destroyed in acidic or highly saline solutions, we studied the stability of the fixation of Arsenazo reagents on the surface of $\mathrm{SiO}_{2}-\mathrm{PHMG}$ in various media.

$\mathrm{SiO}_{2}$-PHMG-Ars was treated with solutions of nitric acid and sodium chloride in a batch mode. The results are shown in Table 1.

As can be seen from the table, the degree of desorption of Arsenazo I after treating with $2 \mathrm{M} \mathrm{HNO}_{3}$ does not exceed $23 \%$, and when treated with $\mathrm{NaCl}$ solution with a concentration of $100 \mathrm{~g} \mathrm{~L}^{-1}$, it is $12 \%$, while the desorption of Arsenazo III under the same conditions is negligible. A stronger fixation of Arsenazo III is due to an increase in the number of acid arseno groups in its composition. Thus, an increase in the number of negatively charged groups leads to stronger bonding due to the formation of a greater number of electrostatic bonds with the guanidine groups of $\mathrm{SiO}_{2}-\mathrm{PHMG}$. 
In both cases, the reagents are fixed rather firmly on the surface of $\mathrm{SiO}_{2}-\mathrm{PHMG}$, which makes it possible to use these adsorbents for the solid-phase extraction of lanthanide ions from weakly acidic and highly saline solutions.

\subsection{Characterization of $\mathrm{SiO}_{2}-\mathrm{PHMG}-\mathrm{Ars}$}

The advantage of the proposed method for modifying the surface of the adsorbent is that the properties of the reagent, which is fixed on the surface, remain almost unchanged. This is confirmed by the overlapping of the UV-Vis spectra of the reagents in solution and the diffuse reflectance spectra on the $\mathrm{SiO}_{2}$-PHMG surface (Fig. 4). Such an overlapping of the spectra indicates the preservation of the chromophore properties of the reagents during their fixing on the surface of $\mathrm{SiO}_{2}-\mathrm{PHMG}^{`}$

Figure 5 shows the IR spectra of $\mathrm{SiO}_{2}, \mathrm{SiO}_{2}-\mathrm{PHMG}$, Arsenazo III, and $\mathrm{SiO}_{2}-$ PHMG-ArsIII. The FT-IR spectra of $\mathrm{SiO}_{2}$ and $\mathrm{SiO}_{2}-\mathrm{PHMG}$ are almost identical. A wide intense band at $1107-1110 \mathrm{~cm}^{-1}$ corresponds to $\mathrm{Si}-\mathrm{O}-\mathrm{Si}$ vibrations, and a band with a maximum at $1640 \mathrm{~cm}^{-1}$ corresponds to deformation vibrations of $\mathrm{OH}$ groups of adsorbed water. Besides the indicated bands, the FT-IR spectrum of the $\mathrm{SiO}_{2}$-PHMG-

ArsIII adsorbent contains bands at $1485-1487 \mathrm{~cm}^{-1}$, which corresponds to vibrations of the $-\mathrm{N}=\mathrm{N}-, 918-920 \mathrm{~cm}^{-1}$ to $-\mathrm{As}=\mathrm{O}$, and $635-665 \mathrm{~cm}^{-1}$ to - As-O. Similar bands are observed in the FT-IR spectrum of Arsenazo III, which confirms the fixation of the reagent on the surface of $\mathrm{SiO}_{2}$-PHMG.

\subsection{Optimization of the conditions for solid-phase extraction of the REE in the}

\section{batch mode}

Lanthanides are quantitatively extracted (95-99\%) by $\mathrm{SiO}_{2}-\mathrm{PHMG}-\mathrm{ArsI}$ adsorbent at pH 5.5-7.0, and $\mathrm{SiO}_{2}-\mathrm{PHMG}-\mathrm{ArsIII}$ at $\mathrm{pH}$ 2.0-6.0 (Fig. 6). As can be seen from the figures, $\mathrm{SiO}_{2}-\mathrm{PHMG}-\mathrm{ArsIII}$ extracts lanthanides from more acidic solutions compared 
to $\mathrm{SiO}_{2}-\mathrm{PHMG}$-ArsI, which is in good agreement with the published data on the optimal $\mathrm{pH}$ range for the formation of complex compounds of lanthanides with Arsenazo reagents in solutions [32-33].

The time of attainment of adsorption equilibrium depended on the initial REE concentration and was $5 \mathrm{~min}\left(\mathrm{C}_{\mathrm{REE}}<5 \mathrm{mg} \mathrm{L}^{-1}\right)$ and $15 \mathrm{~min}\left(\mathrm{C}_{\mathrm{REE}}>5 \mathrm{mg} \mathrm{L}^{-1}\right)$. Kinetic dependences were analyzed by an example of Sm(III) adsorption by the proposed adsorbents using pseudo-first and pseudo-second-order models (Table 2).

The adsorption of Sm(III) by both adsorbents is better described by the kinetic model of the pseudo-second order.

The adsorption capacity of $\mathrm{SiO}_{2}-\mathrm{PHMG}$-Ars adsorbents for $\mathrm{La}(\mathrm{III})$ and $\mathrm{Sm}(\mathrm{III})$ was determined from horizontal sections of adsorption isotherms (Fig. 7) and was 19 and $9 \mu \mathrm{mol} \mathrm{g}^{-1}$ for $\mathrm{SiO}_{2}-\mathrm{PHMG}-\mathrm{ArsI}$ and $\mathrm{SiO}_{2}-\mathrm{PHMG}-\mathrm{ArsIII}$, respectively. The adsorption capacity of the studied adsorbents for La(III) and Sm(III) was determined, since they represent light rare earth elements (LREE) and middle rare earth elements (MREE), respectively.

A comparison of the adsorption capacity for $\mathrm{La}(\mathrm{III})$ and $\mathrm{Sm}(\mathrm{III})$ with the adsorption capacity for Arsenazo I and Arsenazo III suggests that in the case of both adsorbents complexes of the composition Me: $\mathrm{R}=1: 1$ are formed on the surface; complexes of a similar composition are formed in solution [32-34]. REE form more stable complexes with Arsenazo III than with Arsenazo I [34], which affects the distribution constants during their solid-phase extraction using $\mathrm{SiO}_{2}$-PHMG-Ars adsorbents. The distribution coefficients for $\mathrm{La}(\mathrm{III})$ and $\mathrm{Sm}(\mathrm{III})$ were $2.9 \cdot 10^{3}, 5.6 \cdot 10^{3}$ $\mathrm{cm}^{3} \mathrm{~g}^{-1}$ for $\mathrm{SiO}_{2}$-PHMG-ArsI, and $2.2 \cdot 10^{4}, 4.6 \cdot 10^{4} \mathrm{~cm}^{3} \mathrm{~g}^{-1}$ for $\mathrm{SiO}_{2}$-PHMG-ArsIII.

The experimental adsorption isotherms of $\mathrm{La}(\mathrm{III})$ and $\mathrm{Sm}(\mathrm{III})$ using $\mathrm{SiO}_{2}-$ PHMG-Ars were analyzed using the Langmuir and Freindlich models (Table 3). 
In all cases, adsorption isotherms were better described by the Langmuir model, which indicates that adsorption proceeds as a monolayer on the energetically uniform surface.

It is proposed to use the prepared adsorbents for the preconcentration of REE from lignites and products of their processing; therefore, the extraction of accompanying metal ions (Fe(III), $\mathrm{Cu}(\mathrm{II}), \mathrm{Pb}(\mathrm{II}), \mathrm{Zn}(\mathrm{II}), \mathrm{Mn}(\mathrm{II}), \mathrm{Ni}(\mathrm{II})$ ), $\mathrm{Co}(\mathrm{II}), \mathrm{Fe}(\mathrm{II})$, $\mathrm{Na}(\mathrm{I}), \mathrm{K}(\mathrm{I}), \mathrm{Mg}(\mathrm{II}), \mathrm{Ca}(\mathrm{II}), \mathrm{Sr}(\mathrm{II}))$ was studied.

Most ions of non-ferrous and heavy metals were quantitatively extracted (9599\%) by the studied adsorbents at $\mathrm{pH}>5.0$, which allows effective separation of REE from them. An exception was Fe(III), which was recovered at $\mathrm{pH}$ 3.0-4.0. To eliminate the interfering effect of $\mathrm{Fe}(\mathrm{III})$, a $1 \mathrm{M}$ hydroxylamine solution was added to the initial mixture of metal ions, which reduced $\mathrm{Fe}(\mathrm{III})$ to $\mathrm{Fe}(\mathrm{II})$, and $\mathrm{Fe}(\mathrm{II})$ was extracted by the studied adsorbents at $\mathrm{pH}>5.5$. Alkali and alkaline earth metal ions were extracted (3$5 \%)$ by $\mathrm{SiO}_{2}-\mathrm{PHMG}-\mathrm{Ars}$ at $\mathrm{pH}>$ 7.5. SPE of REE (0.1 $\mathrm{g} \mathrm{SiO}_{2}$-PHMG-Ars, $\mathrm{pH}$ 3.5) was not affected by $10^{6}$-fold excess of alkaline metals, $10^{4}$-fold excess of alkaline-earth metals, and salt background up to $10 \mathrm{~g} \mathrm{~L}^{-1}$ for $\mathrm{Na}_{2} \mathrm{SO}_{4}$ or $\mathrm{NaCl}$.

Despite the fact that the adsorption capacity of $\mathrm{SiO}_{2}-\mathrm{PHMG}-\mathrm{ArsI}$ for REE is 2 times greater than the capacity of $\mathrm{SiO}_{2}$-PHMG-ArsIII, it is more appropriate to use an adsorbent modified with Arsenazo III, since quantitative separation of REE from accompanying non-ferrous and a number of other metals was achieved in a slightly acidic conditions ( $\mathrm{pH} 2.5$ ), a significant recovery of which was observed at $\mathrm{pH}>5.5$.

\subsection{Optimization of the conditions for the REE ions solid-phase extraction in} the dinamic mode

The conditions for the dynamic SPE of REE ions using proposed adsorbents were studied. 
For the SPE of REE in dynamic mode, the $\mathrm{pH}$ range was selected, similar to the quantitative extraction in the batch mode, $\mathrm{pH}$ 2.0-6.0. The optimal flow rate of solutions containing REE through a column filled with $0.1 \mathrm{~g}$ of $\mathrm{SiO}_{2}-\mathrm{PHMG}-\mathrm{ArsIII}$ was $1-2 \mathrm{~mL}$ $\min ^{-1}$ (Fig. 8).

The total dynamic capacity of $\mathrm{SiO}_{2}$-PHMG-ArsIII for $\mathrm{Sm}$ (III) was $\sim 9 \mu \mathrm{mol} \mathrm{g}{ }^{-1}$, which correlates with the adsorption capacity in the batch mode.

When passing solutions with a low REE content $\left(0.1 \mathrm{mg} \mathrm{L}^{-1}\right)$ through a column filled with $\mathrm{SiO}_{2}$-PHMG-ArsIII with a flow rate of $1 \mathrm{~mL} \mathrm{~min}^{-1}$, metals are not detected in the effluent even after passing of $1 \mathrm{~L}$ of the solution.

In the dynamic mode, quantitative desorption (99\%) of REE from the surface of $\mathrm{SiO}_{2}$-PHMG-ArsIII was achieved by passing of $10 \mathrm{~mL}$ of $1-2 \mathrm{M} \mathrm{HNO}_{3}(\mathrm{HCl})$ with a flow rate of $1 \mathrm{~mL} \mathrm{~min}^{-1}$ (Table 4).

The degree of desorption of Sm(III) increases with increasing concentration of acid. Subsequently, $2 \mathrm{M} \mathrm{HNO}_{3}$ was used for the desorption of REE from the surface of the adsorbents, and partial desorption of the reagent from the surface also occurred. Arsenazo completely desorbed from the surface during the treatment with hot $6 \mathrm{M}$ $\mathrm{HNO}_{3}(\mathrm{HCl})$, but the PHMG layer remains on the surface of the adsorbent. Such a strong fixation is explained by the fact that the polymer formed many multicenter intermolecular bonds with the surface of silica. Therefore, $\mathrm{SiO}_{2}-\mathrm{PHMG}$ can be retreated with an aqueous reagent solution and used for SPE of REE. Adsorbents can withstand at least 6 cycles of sorption-regeneration without reducing the adsorption capacity.

\subsection{Extraction of REE with $\mathrm{SiO}_{2}-\mathrm{PHMG}$-ArsIII from lignites and their ashes}

Due to the relatively small adsorption capacity of $\mathrm{SiO}_{2}-\mathrm{PHMG}-\mathrm{ArsIII}$ for REE, it is possible to use of the proposed adsorption materials in analytical practice for 
preconcentration of REE and their separation from accompanying metal ions before their determination.

In laboratory analysis, it is necessary to carry out preliminary separation and preconcentration, since the matrix components of the samples have a significant effect on the further determination of REE using ICP-MS.

$\mathrm{SiO}_{2}$-PHMG-ArsIII was successfully used for preconcentration of REE from solutions after digestion of lignite and its ash. The results of the determination of REE in lignites and their ash are given in Table. 5.

The REE content in lignites is relatively low, however, after burning lignite, the content of rare earth elements in ash increases by about 20 times (Table 5), and is 0.25 $\%(\mathrm{w} / \mathrm{w})\left(2500 \mathrm{~g} \mathrm{t}^{-1}\right)$, which allows us to consider lignite ash as a raw material of REE.

\section{Conclusion}

The developed silica based adsorbents, sequentially modified with polyhexamethylene guanidine and Arsenazo I or Arsenazo III, allow the quantitative extraction of REE ions and their separation from non-ferrous and other related metals. The method of adsorbents synthesis is simple, uses aqueous solutions of widespread and available reagents. Organic reagents retain their chromophore and complexing properties after fixing to the surface. The use of a dynamic mode of adsorption allows SPE of REE ions from the bulk solutions. The proposed adsorbents can be used for preconcentration and subsequent determination of REE in other complex solutions.

\section{Disclosure statement}

No potential conflict of interest was reported by authors. 


\section{Funding}

The reported study was funded by RFBR according to the research project № 18-33-00105. This work was supported by the Ministry of Education and Science of the Russian Federation under Grant no. FSRZ-2020-0013 for Siberian Federal University.

\section{References}

1. Zhang, K.; Kleit, A.N.; Nieto, A. An economics strategy for criticality - Application to rare earth element Yttrium in new lighting technology and its sustainable availability. Renew. Sustain. Energy Rev. 2017, 77, 899-915, http://dx.doi.org/10.1016/j.rser.2016.12.127.

2. Goodenough, K.M.; Wall, F.; Merriman, D. The Rare Earth Elements: Demand, Global Resources, and Challenges for Resourcing Future Generations. Nat. Resour. Res. 2018, 27, 201-216, https://doi.org/10.1007/s11053-017-9336-5

3. Kermer, R.; Hedrich, S.; Bellenberg, S.; Brett, B.; Schrader, D.; Schönherr, P.; Köpcke, M.; Siewert, K.; Günther, N.; Gehrke, T.; Sand, W.; Räuchle, K.; Bertau, M.; Heide, G.; Weitkämper, L.; Wotruba, H.; Ludwig, H.-M.; Partusch, R.; Schippers, A.; Reichel, S.; Glombitza, F.; Janneck, E. Lignite ash: Waste material or potential resource - Investigation of metal recovery and utilization options. Hydrometallurgy. 2017, 168, 141-152, https://doi.org/10.1016/j.hydromet.2016.07.002

4. Llorens, J.F.; Fernandez-Turiel, J.L.; Querol, X. The fate of trace elements in a large coal-fired power plant. Environ. Geol. 2001, 40, 409-416, https://doi.org/10.1007/s002540000191.

5. Pentari, D.; Foscolos, A.E.; Perdikatsis V. Trace Elements in the Lignite-bearing Area of Lofoi, Florina Basin, Western Greek Macedonia, Greece. Energ. Source. Part A. 2007, 30, 316-324, https://doi.org/10.1080/15567030600824858. 
6. Hidayah, N.N.; Abidin, S.Z. The evolution of mineral processing in extraction of rare earth elements using solid-liquid extraction over liquid-liquid extraction: A review. Miner. Eng. 2017, 112, 103-113, http://dx.doi.org/10.1016/j.mineng.2017.07.014.

7. Sun, X.; Ji, Y.; Hu, F.; He, B.; Chen, J.; Li, D. The inner synergistic effect of bifunctional ionic liquid extractant for solvent extraction. Talanta. 2010, 81, 18771883, https://doi.org/10.1016/j.talanta.2010.03.041.

8. Xie, F.; Zhang, T.A.; Dreisinger, D.; Doyle, F. A critical review on solvent extraction of rare earths from aqueous solutions. Miner. Eng. 2014, 56, 10-28, https://doi.org/10.1016/j.mineng.2013.10.021.

9. Jha, M.K.; Kumari, A.; Panda, R.; Kumar, J.R.; Yoo, K.; Lee, J.Y. Review on hydrometallurgical recovery of rare earth metals. Hydrometallurgy. 2016, 165, 226, http://doi.org/10.1016/j.hydromet.2016.01.035.

10. Vasylechko, V.O.; Gryshchouk, G.V.; Zakordonskiy, V.P.; Vyviurska, O.; Pashuk, A.V. A solid-phase extraction method using Transcarpathian clinoptilolite for preconcentration of trace amounts of terbium in water samples. Chem. Cent. J. 2015, 9:45, https://doi.org/10.1186/s13065-015-0118-z

11. Bao, Z.; Zhao, Z. Geochemistry of mineralization with exchangeable REY in the weathering crusts of granitic rocks in South China. Ore Geol. Rev., 2008, 33, 519535, https://doi.org/10.1016/j.oregeorev.2007.03.005.

12. Xiong, C.; Meng, Y.; Yao, C.; Shen, C. Adsorption of erbium(III) on D113-III resin from aqueous solutions: batch and column studies. J. Rare Earths. 2009, 27(6), 923-931, https://doi.org/10.1016/S1002-0721(08)60364-6.

13. Xiong, C.; Chen, X.; Yao, C. Enhanced adsorption behavior of Nd(III) onto D113III resin from aqueous solution. J. Rare Earths. 2011, 29(10), 979-985, https://doi.org/10.1016/S1002-0721(10)60582-0. 
14. Sun, X.; Peng, B.; Ji, Y; Chen, J.; Li, D. The solid-liquid extraction of yttrium from rare earths by solvent (ionic liquid) impreganated resin coupled with complexing method. Sep. Purif. Technol. 2008, 63, 61-68, https://doi.org/10.1016/j.seppur.2008.03.038.

15. Karadaş, C.; Kara, D. Preconcentration of rare earth elements using Amberlite XAD-4 modified with 2,6-Pyridinedicarboxaldehyde and their determination by inductively coupled plasma optical emission spectrometry. Water Air Soil Pollut. 2014, 225:1972, https://doi.org/10.1007/s11270-014-1972-3.

16. Ogata T.; Narita, H.; Tanaka, M. Adsorption behavior of rare earth elements on silica gel modified with diglycol amic acid. Hydrometallurgy. 2015, 152, 178-182, https://doi.org/10.1016/j.hydromet.2015.01.005.

17. Ogata, T.; Narita, H.; Tanaka, M. Rapid and selective recovery of heavy rare earths by using an adsorbent with diglycol amic acid group. Hydrometallurgy. 2015, 155, 105-109, https://doi.org/10.1016/j.hydromet.2015.04.015.

18. Ravi, S.; Lee, Y.R.; Yu, K.; Ahn, J.W.; Ahn, W.S. Benzene triamidotetraphosphonic acid immobilized on mesoporous silica for adsorption of $\mathrm{Nd}^{3+}$ ions in aqueous solution. Micropor. Mesopor. Mat. 2018, 258, 62-71 https://doi.org/10.1016/j.micromeso.2017.09.006

19. Polido Legariaa, E.; Saldana, I.; Svedlindhb, P.; Wetterskogb, E.; Gunnarssonb, K.; Kesslera, V.G.; Seisenbaeva, G.A. Coordination of rare earth element cations on the surface of silica-derived nanoadsorbents. Dalton. 2017, 47, 1312-1320, https://doi.org/10.1039/C7DT04388K

20. Kubota, F.; Shimobori, Y.; Koyanagi, Y.; Shimojo, K.; Kamiya, N.; Goto, M. Uphill transport of rare-earth metals through a highly stable supported liquid 
membrane based on an ionic liquid. Anal. Sci. 2010, 26(3), 289-290, https://doi.org/10.2116/analsci.26.289.

21. Cheng, Y.; Zhang, L.; Bian, X.; Zuo, H.; Dong, H. Adsorption and mineralization of REE_lanthanum onto bacterial cell surface. Environ. Sci. Pollut. Res. 2018, 25(23), 22334-22339, https://doi.org/10.1007/s11356-017-9691-0.

22. Challaraj Emmanuel, E.S.; Vignesh, V.; Anandkumar, B.; Maruthamuthu, S. Bioaccumulation of cerium and neodymium by Bacillus cereus isolated from rare earth environments of Chavara and Manavalakurichi, India. Indian J. Microbiol. 2011, 51(4), 488-495, https://doi.org/10.1007/s12088-011-0111-8.

23. Moriwaki, H.; Yamamoto, H. Interactions of microorganisms with rare earth ions and their utilization for separation and environmental technology. Appl. Microbiol. Biotechnol. 2013, 97(1), 1-8, https://doi.org/10.1007/s00253-012-4519-9.

24. Ramasamy, D.L.; Puhakka, V.; Iftekhar, S.; Wojtuś, A.; Repo, E.; Ben Hammouda S.; Iakovleva, E.; Sillanpää, M. N- and O- ligand doped mesoporous silica-chitosan hybrid beads for the efficient, sustainable and selective recovery of rare earth elements (REE) from acid mine drainage (AMD): Understanding the significance of physical modification and conditioning of the polymer. J. Hazard. Mater. 2018, 348, 84-91, https://doi.org/10.1016/j.jhazmat.2018.01.030.

25. Dolatyari, L.; Yaftian, M.R.; Rostamnia, S. Adsorption characteristics of Eu(III) and Th(IV) ions onto modified mesoporous silica SBA-15 materials. J. Taiwan Inst. Chem. E. 2015, 60, 174-184, https://doi.org/10.1016/j.jtice.2015.11.004

26. Anastopoulos, I.; Bhatnagar, A.; Lima, E.C. Adsorption of Rare Earth Metals: A review of recent literature. J. Mol. Liq. 2016, 221, 954-962, https://doi.org/10.1016/j.molliq.2016.06.076. 
27. Macka, M.; Nesterenko, P.; Andersson, P.; Haddad, P.R. Separation of uranium(VI) and lanthanides by capillary electrophoresis using on-capillary complexation with arsenazo III. J. Chromatogr. A. 1998, 803, 279-290, https://doi.org/10.1016/S00219673(97)01226-0.

28. Lu, Y.W.; Laurent, G.; Pereira, H. A novel methodology for evaluation of formation constants of complexes: example of lanthanide-Arsenazo III complexes. Talanta. 2004, 62, 959-970, https://doi.org/10.1016/j.talanta.2003.10.030.

29. Rohwer, H.; Collier, N.; Hosten, E. Spectrophotometric study of arsenazo III and its interactions with lanthanides. Anal. Chim. Acta. 1995, 314, 219-223, https://doi.org/10.1016/0003-2670(95)00279-9.

30. Hosten, E.; Rohwer, H. Interaction of anions with arsenazo III-lanthanide (III) complexes. Anal. Chim. Acta. 1997, 345, 227-233, https://doi.org/10.1016/S00032670(97)00100-1.

31. Ivanov, V.M.; Ermakova, N.V. Optical and colorimetric characteristics of erbium complexes with Arsenazo I, Arsenazo III, and Chlorophosphonazo III. Mosc. Univ. Chem. Bull. 2000, 41, 174-177.

32. Rohwer, H.; Hosten, E. pH dependence of the reactions of arsenazo III with lanthanides. Anal. Chim. Acta. 1997, 339, 271-277, https://doi.org/10.1016/S00032670(96)00471-0

33. Muk, A.; Radosavljević, R. Formation of metal complexes with the Arsenazo I and Arsenazo III reagents as function of the medium acidity. Croat. Chem. Acta. 1967, 39, 1-9, https://hrcak.srce.hr/208102

34. Basargin, N.N.; Ivanov, V.M.; Kuznetsov, V.V.; Mikhailova, A.V. 40 years since discovery of the arsenazo III reagent. J. Anal. Chem. 2000, 55(3) 204-210, https://doi.org/10.1007/BF02757200 


\section{Figure caption}

Figure 1. The scheme of the silica based adsorbent, modified with polyhexamethylene guanidine and Arsenazo III

Figure 2. The dependence of Arsenazo I (1) and Arsenazo III (2) extraction by the $\mathrm{SiO}_{2}-\mathrm{PHMG}$ vs. concentration of $\mathrm{HNO}_{3}$ and $\mathrm{pH}\left(0.1 \mathrm{~g}\right.$ of $\mathrm{SiO}_{2}-\mathrm{PHMG}$ adsorbent, $\mathrm{C}_{\text {Arsenazo }}=1 \cdot 10^{-6} \mathrm{M}, \mathrm{V}=10 \mathrm{~mL}$, contact time $10 \mathrm{~min}$ )

Figure 3. Adsorption isotherms of $\mathrm{SiO}_{2}-\mathrm{PHMG}$ for Arsenazo I (1) and Arsenazo III (2) $(\mathrm{V}=10 \mathrm{~mL}, 0.1 \mathrm{~g}$ of adsorbent, contact time $10 \mathrm{~min}, \mathrm{pH} 4.5)$

Figure 4. UV-Vis spectrum (2) of an aqueous solution of Arsenazo I (a) and Arsenazo III (b) and diffuse reflectance spectrum (1) of $\mathrm{SiO}_{2}-\mathrm{PHMG}-\mathrm{ArsI}$ (a) and $\mathrm{SiO}_{2}-\mathrm{PHMG}-$ ArsIII (b) with photographs of the cuvette with solution and of the adsorbent under an optical microscope

Figure 5. FT-IR spectra of $\mathrm{SiO}_{2}, \mathrm{SiO}_{2}-\mathrm{PHMG}$, Arsenazo III and $\mathrm{SiO}_{2}-\mathrm{PHMG}-\mathrm{ArsIII}$ Figure 6. The dependence of REE extraction by the $\mathrm{SiO}_{2}-\mathrm{PHMG}-\mathrm{ArsI}$ (a) and $\mathrm{SiO}_{2}-$ PHMG-ArsIII (b) vs. $\mathrm{pH}\left(0.1 \mathrm{~g}\right.$ of $\mathrm{SiO}_{2}$ - PHMG adsorbent, $\mathrm{C}_{\mathrm{REE}}=0.1 \mathrm{mg} \mathrm{L}{ }^{-1}, \mathrm{~V}=10$ $\mathrm{mL}$, contact time $10 \mathrm{~min}$ )

Figure 7. Adsorption isotherms of $\mathrm{SiO}_{2}-\mathrm{PHMG}-\mathrm{ArsI}$ (1) and $\mathrm{SiO}_{2}-\mathrm{PHMG}-\mathrm{ArsIII}$ (2) for $\mathrm{La}(\mathrm{III})$ (a) and $\mathrm{Sm}(\mathrm{III})(\mathrm{b})(\mathrm{V}=10 \mathrm{~mL}, 0.1 \mathrm{~g}$ of adsorbent, contact time $30 \mathrm{~min}, \mathrm{pH} 5.5$ (AI), $\mathrm{pH} 2.5$ (AIII))

Figure 8. Effect of the flow rate on the Sm(III) (a) and group of REE (b) SPE using

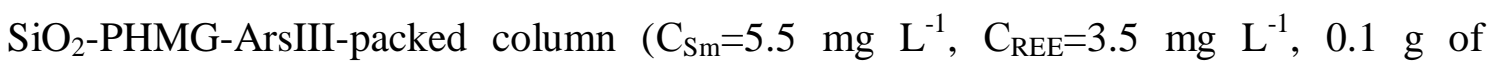
adsorbent, $\mathrm{pH} 2.5$ ) 